Thorax, 1977, 32, 717-719

\title{
A trial of clenbuterol in bronchial asthma
}

\author{
G. ANDERSON AND E. WILKINS
}

From St. Woolos Hospital, Newport, Gwent, UK

Anderson, G. and Wilkins, E. (1977). Thorax, 32, 717-719. A trial of clenbuterol in bronchial asthma. Clenbuterol is a $\beta_{2}$-sympathomimetic bronchodilator. In a double-blind cross-over trial in 19 asthmatic patients with reversible airways obstruction, oral administration of both clenbuterol $(40 \mu \mathrm{g})$ and salbutamol $(4 \mathrm{mg})$ caused significantly greater increases in peak expiratory flow rate (PEFR) than placebo, that of clenbuterol lasting longer. The patients' subjective assessment also suggested the relief of their symptoms by the active drugs. Side-effects were minimal.

Clenbuterol is a recently synthesised sympathomimetic agent with a specific affinity for the $\beta_{2^{-}}$ adrenergic receptors in the bronchial musculature. Animal studies have shown that its bronchodilator action is more prolonged than that of orciprenaline and salbutamol (Engelhardt, 1976). The purpose of this study was to compare in a double-blind cross-over manner the effects of clenbuterol, salbutamol, and placebo in patients with bronchial asthma.

\section{Patients and methods}

Nineteen patients with bronchial asthma were studied. All showed an improvement in peak expiratory flow rate (PEFR) exceeding $15 \%$ five minutes after inhaling 2 puffs $(0.16 \mathrm{mg})$ of isoprenaline. The characteristics of the patients are shown in Table 1. All bronchodilator drugs were stopped at least 10 hours before the trial, but patients taking corticosteroids and sodium cromoglycate continued to do so.

After giving informed consent patients were trained to record PEFR following the method of Lal et al. (1974). On a practice day before the trial they were instructed on rising to make three technically acceptable readings of PEFR at 10-

Table 1 Details of patients studied

Total no. of patients

Males

Age, years (mean and range)

Positive skin tests

Blood eosinophilia $\left(>0.5 \times 10^{\circ} / 1\right)$

Steroid treatment during trial

Cromoglycate treatment during trial minute intervals until two consecutive readings were within $10 \mathrm{l} / \mathrm{min}$. The higher reading was accepted as a basal value (time 0). Three PEFRs were recorded 10, 20, and 30 minutes and 1, 2, 3, $4,6,8$, and 10 hours after the basal value. Values were recorded on a standard form together with a record of any side-effects and the time of their occurrence.

Patients recorded a subjective impression of their breathing during the test day. This was compared to that on the day before the trial and scored as 1 , worse; 2 , no change; 3 , a little better; 4 , much better; 5 , very much better. Patients were told to contact the physician if any difficulties were experienced during the trial period.

After completing the practice day patients were studied over three consecutive days and were given sealed packets each containing three tablets, two white and one coloured. Each patient was given in random order the following drugs: placebo day, two white tablets (placebo) and one blue tablet (placebo); salbutamol day, two white tablets (placebo) and one pink tablet (4 mg salbutamol); clenbuterol day, two white tablets $(2 \times 20 \mu \mathrm{g}$ clenbuterol) and one yellow tablet (placebo). It has been shown that salbutamol, $4 \mathrm{mg}$, gives a bronchodilatation effect equivalent to clenbuterol, 40 $\mu \mathrm{g}$ (Kamburoff et al., 1977). The tablets were taken between 0800 and 0900 hours, immediately after obtaining basal values for PEFR. PEFR was then recorded at the same intervals as on the practice day and similar recordings were made of sideeffects and breathing scores. Patients were studied as outpatients and were interviewed after the practice day to ensure that they were able to cope with the methods of the trial. 
Analysis of variance was carried out at each time-point on the patients' PEFR readings, and Duncan's multiple range test was used to investigate further any differences between treatments. Subjective assessments of breathing were analysed by a Friedman two-way analysis of variance (Siegel, 1956).

\section{Results}

The results of mean PEFR in 19 patients are shown in Table 2. During the placebo day there was a slow rise in PEFR until four hours after recording the basal values, when a plateau was reached. These increases were significant $(P<0.05)$ at 10 minutes and from one to eight hours.

Table 2 Mean PEFR in 19 patients

\begin{tabular}{|c|c|c|c|}
\hline \multirow{2}{*}{$\begin{array}{l}\text { Time after } \\
\text { ingestion of } \\
\text { tablets (min) }\end{array}$} & \multicolumn{3}{|c|}{ Mean $\%$ change $( \pm 1 S E)$} \\
\hline & Clenbuterol & Salbutamol & Placebo \\
\hline $\begin{array}{r}10 \\
20 \\
30 \\
60 \\
120 \\
180 \\
240 \\
360 \\
480 \\
600\end{array}$ & $\begin{array}{r}5.4 \pm 2.5 \\
9.8 \pm 3.2 \\
17.4 \mathrm{ab} \pm 5.0 \\
27.9 \mathrm{ab} \pm 4.8 \\
40.0 \mathrm{a}^{*} \pm 10.7 \\
44.8 \mathrm{a} \pm 13.5 \\
51.5 \mathrm{a} \pm 16.8 \\
48.7 \mathrm{a}^{*} \pm 13.8 \\
53.8 \mathrm{a}^{*} \pm 18.8 \\
41.8 \mathrm{a}^{*} \pm 10.9\end{array}$ & $\begin{array}{l}7.3 \quad \pm 3.7 \\
14.5 \quad \pm 4.5 \\
20.5 a \pm 4.6 \\
33.6 a^{*} \pm 6.8 \\
40.3 a^{*} \pm 7.5 \\
39.9 a^{*} \pm 7.8 \\
35.9 a \pm \pm 8.0 \\
34.5 a * \pm 7.9 \\
34.0 a \pm \pm 9.7 \\
26.6 a b \pm 8.7\end{array}$ & $\begin{array}{r}4.8 \pm 2.3 \\
2.9 \quad \pm 3.3 \\
4.9 b \pm 3.6 \\
8.8 b^{*} \pm 3.9 \\
12.7 b^{*} \pm 4.5 \\
17.8 b^{*} \pm 5.5 \\
17.7 b \pm 4.8 \\
12.2 b^{*} \pm 4.6 \\
15.9 b^{*} \pm 4.5 \\
11.3 b^{*} \pm 6.1\end{array}$ \\
\hline
\end{tabular}

If any two treatments at the same time point do not have a common letter they are significantly different $(P<0.05)$.

${ }^{*} \mathrm{P}<0.01$.

With salbutamol there was a significant $(P<0.05)$ increase above the baseline values from 20 minutes onwards, the increase being highly significant $(P<0.01)$ from 30 minutes to eight hours. Clenbuterol showed a significant increase at every timepoint, the increase being highly significant $(P<0.01)$ from 20 minutes to 10 hours.

With both salbutamol and clenbuterol there were significant $(P<0.05)$ differences from placebo values from two to eight hours. For clenbuterol alone this difference was significant $(P<0.01)$ at 10 hours, and for salbutamol alone significant differences were seen at 30 minutes $(P<0.05)$ and one hour $(P<0.01)$. The differences between the effects of clenbuterol and salbutamol were not quite significant, but were almost so at eight hours.

The results of the breathing scores are shown in Table 3. Eighteen patients produced satisfactory records. While there is an apparent improvement with the active drugs this was not significant. The incidence and nature of side-effects is shown in Table 4. The differences between the number of
Table 3 Results of breathing scores

\begin{tabular}{lllll}
\hline Result & & Clenbuterol & Salbutamol & Placebo \\
\hline Very much better & $(5)$ & 1 & 1 & 0 \\
Much better & $(4)$ & 6 & 7 & 4 \\
A little better & $(3)$ & 8 & 6 & 3 \\
No change & $(2)$ & 3 & 4 & 10 \\
Worse & $(1)$ & 0 & 0 & 1 \\
\hline
\end{tabular}

Table 4 Side-effects in 19 patients

\begin{tabular}{llll}
\hline Side-effect & Clenbuterol & Salbutamol & Placebo \\
\hline Tremor & 4 & 3 & 1 \\
Headache & 2 & 0 & 2 \\
Dizziness & 1 & 0 & 1 \\
Feeling of warmth & 2 & 1 & 0 \\
Cough & 1 & 0 & 1 \\
Nasal discharge & 0 & 1 & 0 \\
Chest pain & 0 & 0 & 1 \\
\hline
\end{tabular}

side-effects with placebo (6), salbutamol (5), and clenbuterol (10) were not quite significant.

\section{Discussion}

Oral administration of clenbuterol and salbutamol produced a significantly better bronchodilatation than did placebo. This effect was present for up to eight hours with salbutamol and for up to 10 hours with clenbuterol, suggesting a longer duration of $\overrightarrow{\overrightarrow{0}}$ action of the latter. The prolonged effect of clenbuterol accords with the results of pharmacokinetic studies in man, where a plasma half-life of about 35 hours has been demonstrated (Zimmer, 1976). Clenbuterol is not subject to the action of catechol-o-methyl transferase and this partly ex- ? plains its prolonged action, which may also be a $\frac{0}{3}$ function of its firm binding at the $\beta$-receptor (Engelhardt, 1976). The long plasma half-life and consequent cumulative effect may allow small

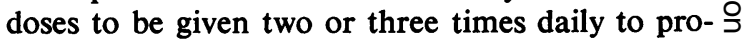
duce an effect equivalent to the single doses of $\frac{D}{O}$ $40 \mu \mathrm{g}$ in this study.

The increase in PEFR with placebo treatment $N$ was also noted by Salorinne et al. (1975), who attributed it to a combination of the normal diurnal variation of PEFR in asthma and placebo $\omega$ effect. With both salbutamol and clenbuterol the side-effects were minor.

We are grateful to Boehringer Ingelheim Limited for $\stackrel{?}{?}$ supplies of the drugs and to Dr. Gordon Cox for 7 advice on the manuscript.

\section{References}

Engelhardt, Von G. (1976). Pharmakologisches Wirkungsprofil von NAB 365 (Clenbuterol), einem neuen 
Broncholytikum mit einer selektiven Wirkung auf die adrenergen beta 2-Rezeptoren. ArzneimittelForschung, 26, 1404-1420.

Kamburoff, P. L., Prime, F. J., and Schmidt, O. P. (1977). The bronchodilator effect of NAB 365. British Journal of Clinical Pharmacology, 4, 67-71.

Lal, S., Dash, C. H., and Gribben, M. D. (1974). An economical method of comparing inhaled bronchodilators in reversible diffuse airways obstruction. Thorax, 29, 317-322.

Salorinne, Y., Stenius, B., Tukiainen, P., and Poppius, Double-blind cross-over comparison of clenbuterol and salbutamol tablets in asthmatic out-patients.
H. (1975). European Journal of Clinical Pharmacology, 8, 189-195.

Siegel, S. (1956). Non parametric Statistics for the Behavioral Sciences. McGraw-Hill, New York.

Zimmer, A. (1976). Einmalapplikation, Mehrfachapplikation und Metabolitenmuster von Clenbuterol beim Menschen. Arzneimittel-Forschung, 26, 14461450 .

Requests for reprints to: Dr. G. Anderson, Chest Research Department, Newport Chest Clinic, 129 Stow Hill, Newport, Gwent NPT 4GA, UK. 